\title{
Correction to: Relationship between in-hospital event rates and high bleeding risk score in patients undergoing primary percutaneous coronary intervention for acute myocardial infarction
}

\author{
Tomofumi Tsukizawa $^{1}$ [ $\cdot$ Masahiko Fujihara ${ }^{1}$
}

Published online: 31 August 2021

(c) Japanese Association of Cardiovascular Intervention and Therapeutics 2021

\section{Correction to: Cardiovascular Intervention and Therapeutics https://doi.org/10.1007/s12928-021-00805-3}

The article Relationship between in-hospital event rates and high bleeding risk score in patients undergoing primary percutaneous coronary intervention for acute myocardial infarction, written by Tomofumi Tsukizawa and Masahiko Fujihara, was originally published online on the publisher's internet portal on 18 August 2021 with Open Access under a Creative Commons Attribution 4.0 International License.
With the author's/authors' decision to cancel Open Access, the copyright of the article changed on 21 August 2021 to (C) Japanese Association of Cardiovascular Intervention and Therapeutics 2021 with all rights reserved.

The original article has been corrected.

The original article can be found online at https://doi.org/10.1007/ s12928-021-00805-3.

Tomofumi Tsukizawa

tm_bbc@yahoo.co.jp

1 Department of Cardiology, Kishiwada Tokushukai Hospital,

4-27-1 Kamori-cho, Kishiwada, Osaka 596-0042, Japan 